\title{
Biochemical Analysis for the Determination of Renal and Pancreatic Disorders in Dogs
}

\author{
Nisha Sharma ${ }^{1}$ and Mukti N. Shrestha ${ }^{2}$ \\ Vet Clinic, Krishnagalli, Lalitpur \\ e-mail: nightjasmine94@yahoo.com
}

\begin{abstract}
A study was conducted to evaluate the renal and pancreatic disorders in the dogs from September to December 2010. One hundred serum samples were collected from one hundred dogs showing the common signs and symptoms of renal and pancreatic disorders. All the serum samples were analyzed in the Laboratory of the Vet Clinic, Krishnagalli, Lalitpur. The biochemical analysis for kidney function tests was Blood urea nitrogen (BUN) and serum creatinine whereas for pancreatic disorders was alpha amylase test. The result showed the higher prevalence of both renal and pancreatic disorders together (25\%) followed by pancreatic disorder which (24\%) and renal disorders was (14\%). Among breeds, pure breeds were found to have higher prevalence for both renal and pancreatic disorders (25.6\%). Mongrels were found to have higher prevalence of pancreatic disorders (50\%), and cross breeds had higher prevalence for renal disorders (38 \%.) Among the pure breeds, German Shepherd had the higher prevalence. In sexwise distribution, males were more vulnerable than females. In the agewise prevalence, age groups of 5-10 were found to be more vulnerable for renal disorders followed by $10-15$ and $0-5$ years age group. Similarly, age groups of 10-15 were found to be highly vulnerable for pancreatic disorders followed by 5-10 and 0-5 years age group. This study, showed range value of BUN, Creatinine, and Alpha amylase were found to be $7-227 \mathrm{mg} / \mathrm{dl}, 0.6-41 \mathrm{mg} / \mathrm{dl}$ and $112-2686 \mathrm{IU} / \mathrm{L}$ respectively.
\end{abstract}

Key words: clinic, laboratory tests, prevalence, serum sample, vulnerable

\section{Introduction}

The term renal function tests include those tests in which various functions of kidney are measured by biochemical means. The estimation of the level of urea in blood is most commonly used but tests for nonprotein nitrogen or creatinine are also available. The levels do not rise appreciably above the normal range until 60 to $75 \%$ of nephrons are destroyed (Godkar \& Godkar 2005). The kidneys excrete the end products of tissue metabolism and maintain homeostasis of fluid and electrolyte metabolism, including acid base balance. Disease conditions in kidneys, urinary bladder and urethra cause renal insufficiencies (Blood et al. 2005). Creatinine is synthesized in liver, kidney and pancreas, and is transported to main brain and muscle. About $1-2 \%$ of total muscle creatinine pool is converted daily to creatinine through the spontaneous non-enzymatic loss of water. It is Non Protein Nitrogen (NPN) substance formed during metabolism of muscle creatinine and phosphocreatinine. Since creatinine is not excreted or absorbed by renal tubules, it can be used as rough index of Glomerular Filtration Rate (GFR). Serum concentration of creatinine between $1-2 \mathrm{mg} /$ 
$100 \mathrm{ml}$ is usually considered normal (Benjamin 1985). Urea is a nitrogenous waste product which is formed in the liver as the end product of amino acid break down. Thus formed urea is transported in the plasma to the kidneys where it is excreted in the urine. This 'in transit' urea is what is being measured in plasma sample (Kerr 2002).

The pancreas makes amylase (alpha-amylase) to hydrolyze dietary starch into disaccharides and trisaccharides which are converted by other enzymes to glucose to supply the body with energy (Hill \& Needham 2002). Serum amylase is the most significant laboratory aid in the diagnosis of acute pancreatitis or exacerbations of a chronic pancreatitis. Dogs excrete very little amylase in the urine in contrast to humans where urine levels of the enzyme may be valuable in assessing the progress of a case of pancreatitis (Hill \& Needham 2002).

\section{Methodology}

The site of study was the Vet Clinic which is located at Krishnagalli, Patan, Lalitpur of Kathmandu Valley. Samples were collected from different dogs showing common signs and symptoms and the entire serological tests were performed. The study was conducted in 100 sick dogs that were brought in the clinic. The dogs showing following symptoms were selected for collections the samples.

\section{Signs and symptoms for renal disorders}

- Intermittent recurrent abdominal or gastrointestinal upsets, anorexia, vomiting, diarrhea, constipation, ascites, alopecia, abnormal urination (color, urine, frequency), polydipsia, polyurea, dysurea, abdominal pain bleeding problems, Chronic weight loss or wasting, uremic smell from the body and breath

\section{Signs and symptoms for pancreatic disorders}

- Abdominal pain, chills, clammy skin, fatty stools, fever, mild jaundice, nausea, weakness, weight loss,vomiting (Dugdale 2010).

\section{Materials used in laboratory}

Chemistry analyzer- Biochemical Analyzer Chem-5v3 was used for analyzing the collected samples. The blood samples were collected from the suspected cases showing any two or more of the common signs and symptoms. From the collected serum samples biochemical tests were performed like Creatinine, and alpha amylase values were obtained.

\section{Data analysis}

The data were summarized using a statistical tool such as STATISTIX software and Microsoft Excel. They were subjected to be analyzed the mean difference using one- way ANOVA. Descriptive statistics such as simple frequency, percentage, and mean were used. They were also presented in bar diagrams, tables, graphs and pie charts.

\section{Results and Discussions}

Total 100 samples from sick dogs brought to the clinic were analyzed for renal and pancreatic disorders for the study.

\section{Prevalence of renal and pancreatic disorders}

Out of 100 samples analyzed for the renal and pancreatic disorders, 63 samples were abnormal and 37 samples were normal for both disorders.
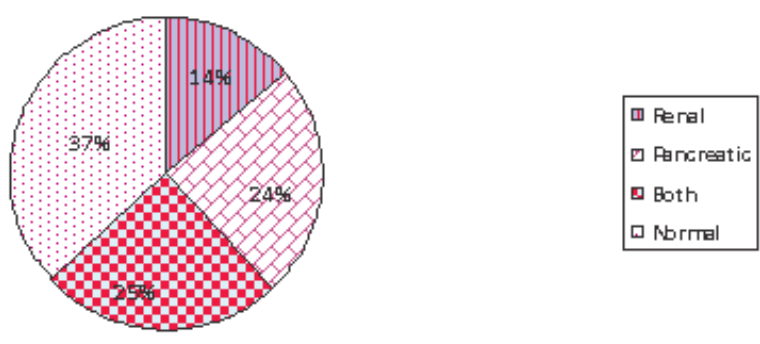

Fig. 1. Prevalence of renal and pancreatic disorders

In this study, prevalence of renal disorders was found to be lower (14\%) as compared to Rai (2008) which was $24 \%$. This may be because of the low sample size in case of Rai i.e. 50.

Incidence of renal and pancreatic disorders was found to be higher in dogs. The main predisposing factors 
might be due to inadequate knowledge about dog management, nutrition, care and health. Indiscriminate uses of drugs by non qualified veterinary practitioners like Junior Technicians (JTs) and Junior Technical Assistants (JTAs) without laboratory based diagnosis might have caused these conditions. Pancreatitis is more commonly observed in obese dogs and those which are given a low protein diet and high fat diet. In this disease, enzymes secreted by the pancreas, start damaging the tissue organ itself (Pancreatitis in Dogs 2011). So the improper management must have created the pancreatic disorders.

\section{Breedwise prevalence of renal and pancreatic disorders}

Breed samples were divided into three broad groups pure, cross and mongrel. In cross breeds, 38\%, 13\% and $25 \%$ were found abnormal for renal, pancreatic and both disorders respectively. In mongrels, $10 \%$, $50 \%$ and $10 \%$ were abnormal for Renal, Pancreatic and both disorders respectively. In pure breeds, 5\%, 17\% and $25.6 \%$ were found abnormal for renal, pancreatic and both disorders respectively (Table 1).

Table 1. Breed wise distributions of renal and pancreatic disorders

\begin{tabular}{l|l|l|l}
\hline & $\begin{array}{l}\text { Pure (\%) } \\
\text { Total case = 82 }\end{array}$ & $\begin{array}{l}\text { Cross (\%) } \\
\text { Total case= 8 }\end{array}$ & $\begin{array}{l}\text { Mongrel (\%) } \\
\text { Total case= 10 }\end{array}$ \\
\hline Renal & 5 & 38 & 10 \\
Pancreatic & 17 & 13 & 50 \\
Both & 25.6 & 25 & 10 \\
\hline
\end{tabular}
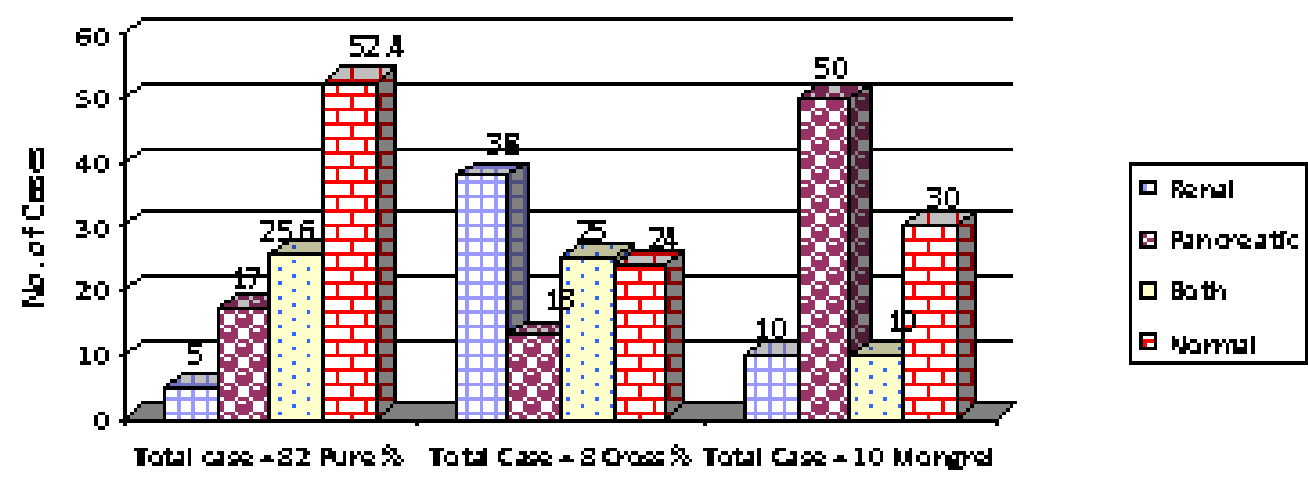

\&

Fig. 2. Breed - wise prevalence of renal and pancreatic disorders

Among the breeds, mongrels were found to be more vulnerable for pancreatic disorders than pure and cross breeds, and cross breeds were found vulnerable for renal disorders than pure and mongrel. This is similar to the study done by Rai (2008). More vulnerability of mongrels may be due to less attraction of people to take care. They are kept mainly outdoors and are fed leftovers. They might have been exposed to toxic substances, ectoparasiticides, etc. as they are mostly reared in free conditions.
Cross breeds were in second position to be affected. It might be due to inadequate knowledge about the feeding (giving more than required amount of protein). The appropriate amount of protein and restricting the excess protein feed would delay the end- stage disease in patients with progressive renal insufficiency (Anderson 1986). Pure breeds were found to have higher incidence of both renal and pancreatic disorder. Pure breeds of dogs inherit a genetic predisposition for these disorders (Fogle 2002). 


\section{Prevalence of renal and pancreatic disorders in pure breeds}

Out of 82 samples taken, abnormal samples for both disorders were 40. Among which highest prevalence was found in German Shepherd (43\%) followed by Labrador (17\%), Cocker Spaniel, Dalmatian, Golden Retriever, Japanese Spitz and Lhasa Apso (5\%), Tibetan Mastiff, Pug and Boxer (4\%). Pomerian, Great Dane and Doberman (1\%) fig. 3.
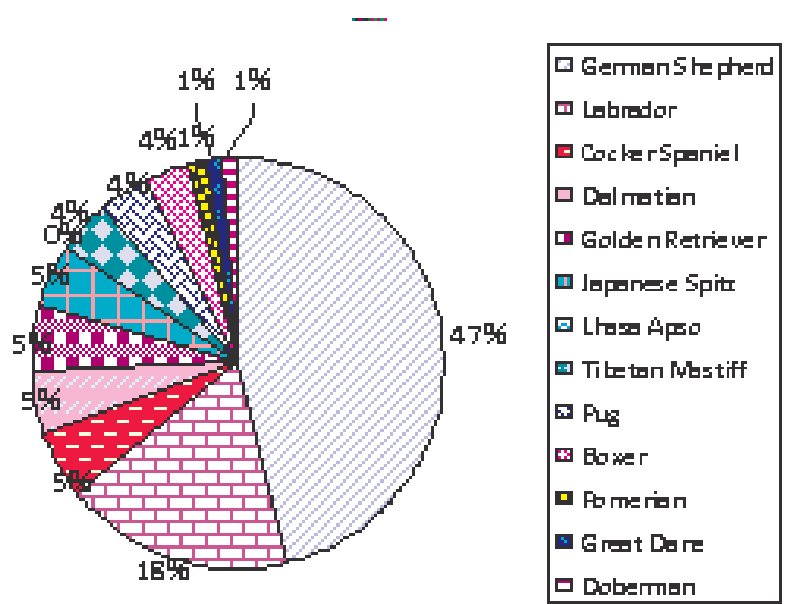

Fig. 3. Prevalence of renal and pancreatic disorders in pure breeds

Among pure breeds, German shepherd was found to have higher prevalence. This might be due to preference of people for owning German shepherd. Some medications like prednisone, azathioprine, and overuse of calcium supplementation can be risk for developing pancreatitis (pancreatitis in dogs 2011).

\section{Sexwise distribution of renal and pancreatic disorders}

Out of 71 cases in males, 42 cases were abnormal. Out of which 4 were abnormal for renal disorders, 20 were abnormal for pancreatic disorders 18 were abnormal for both disorders, and 29 cases were found normal. Out of 29 females, 16 were found abnormal. Out of which 6 were abnormal for renal disorders, 5 for pancreatic disorders only, 5 were for both disorders, and 13 were found normal fig. 4.

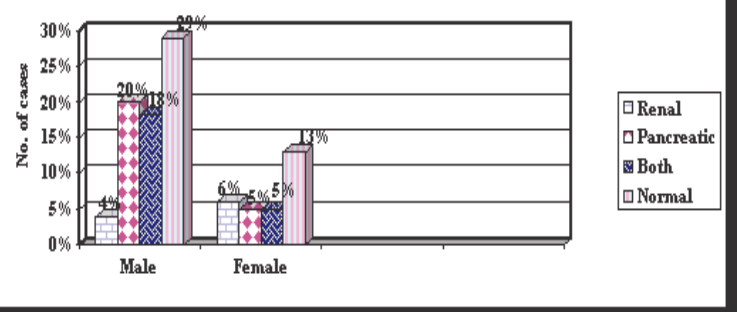

Fig. 4 Sexwise distributions of renal and pancreatic disorders.

Sex wise prevalence showed higher incidence in male than female. This might be due to unequal sample size of male and female dogs as more preference is given to male dogs in our context. People feel trouble to keep females because of their menstrual bleeding problems.

\section{Age wise presentation of renal function Tests}

Dogs were divided into three groups according to their age- 0 -5 years, 5-10 years, and 10-15 years and is presented in the table 2

Table 2 Agewise presentation of renal function tests of abnormal samples

\begin{tabular}{l|l|l|l|l|l|l}
\hline Age & No. of cases & & $\begin{array}{l}\text { Creatinine } \\
(\mathbf{m g} / \mathbf{d l})\end{array}$ & No. of cases & & $\begin{array}{l}\text { BUN } \\
(\mathbf{m g} / \mathbf{d l})\end{array}$ \\
\hline $\begin{array}{l}0-5 \\
\text { years }\end{array}$ & 7 & $\begin{array}{l}\text { Mean } \\
\text { S.D }\end{array}$ & $\begin{array}{l}2.6 \\
1.44\end{array}$ & 8 & $\begin{array}{l}\text { Mean } \\
\text { S.D }\end{array}$ & $\begin{array}{l}66.39 \\
60.05\end{array}$ \\
\hline $5-10$ & 13 & Mean & 7.66 & 15 & Mean & 91.46 \\
\hline years & & S.D & 10.77 & & S.D & 69.55 \\
\hline $10-15$ & 7 & Mean & 4.33 & 6 & $\begin{array}{l}\text { Mean } \\
\text { S.D }\end{array}$ & 70.74 \\
years & & S.D & 3.94 & & & 72.82 \\
\hline
\end{tabular}


Nisha Sharma \& Mukti N Shrestha/Biochemical Analysis.......

Among the three age groups, 5-10 years of age group were found to be more affected than other age groups. Discovery of renal disease in young animals typically raises the question of whether the disease is congenital; however juvenile animals can be affected by acquired renal disorders. Additionally, congenital renal diseases sometimes don't produce clinical signs until affected animals are middle aged or older. Thus, patient's age by itself is not reliable indicator of where an animal with renal disease has congenital lesions (Baumal et al. 1991). The glomerular filtration and blood flow rates decline in linear fashion and the incidence of sclerotic glomeruli increases with advancing age. The ageing kidney is at high risk of failure when functioning nephron numbers are reduced (Anderson
1986). In older patients creatinine is reduced because of decreased muscle mass (Pagana 1998). It may be the reason for increased creatinine level in 5-10 years age group.

\section{Agewise presentation of alpha amylase tests}

Dogs were divided into three age groups to determine alpha amylase tests. In 0-5 year age group, abnormal samples were 13 followed by 22 abnormal samples in 5 -10 years, whereas 8 samples were found abnormal in 10- 15 years age group. Their mean along with their standard deviation (S.D) are presented in Table 3.

Table 3. Agewise presentation of alpha amylase tests of abnormal samples

\begin{tabular}{l|l|l|l}
\hline Age & No. of cases & & $\begin{array}{l}\text { Alpha amylase } \\
(\mathbf{m g} / \mathbf{d l})\end{array}$ \\
\hline $0-5$ years & 13 & $\begin{array}{l}\text { Mean } \\
\text { S.D. }\end{array}$ & $\begin{array}{l}1384.07 \\
306.0\end{array}$ \\
\hline $5-10$ years & 22 & $\begin{array}{l}\text { Mean } \\
\text { S.D. }\end{array}$ & $\begin{array}{l}1451.63 \\
375.43\end{array}$ \\
\hline $10-15$ years & 8 & $\begin{array}{l}\text { Mean } \\
\text { S.D. }\end{array}$ & $\begin{array}{l}1633.25 \\
362.30\end{array}$ \\
\hline
\end{tabular}

Age wise presentation of pancreatic disorders shows the higher occurrences in the age group of 10-15 years. Generally, the middle aged or older and obessed dogs are found to be more prone to suffer from pancreatitis. A number of vital organ systems are at risk in older patients. In addition, diabetes mellitus, a disorder characterized by a deficiency of insulin activity, may occur more often in dogs 7 to 9 years of age (CNM, 1998).

\section{Range value obtained in Kidney Function Tests and Amylase Tests}

Minimum and maximum values of kidney functions test obtained for; creatinine and Blood Urea Nitrogen (BUN) were $0.6-41 \mathrm{mg} / \mathrm{dl}$ and $7-227 \mathrm{mg} / \mathrm{dl}$. Similarly, 1122686IU/L was the value for the alpha amylase tests as presented in the table 4 .

Table 4. Range value obtained in kidney functions tests and alpha amylase test

\begin{tabular}{l|l|l|l|l}
\hline $\begin{array}{l}\text { Biochemical } \\
\text { parameters }\end{array}$ & Unit & Kidney function tests & Alpha amylase tests & Normal range \\
\hline BUN & $\mathrm{mg} / \mathrm{dl}$ & $7-227$ & & $6-21$ \\
\hline Creatinine & $\mathrm{mg} / \mathrm{dl}$ & $0.6-41$ & & $0.6-1.5$ \\
\hline Alpha amylase & $\mathrm{IU} / \mathrm{L}$ & & $112-2686$ & $0-1104$ \\
\hline
\end{tabular}


BUN was found in the range of 7-227 mg/dl. BUN exceeding 35-45 mg/dl indicates kidney disorders. It could be over 100mg/dl (Benjamin 1986). Creatinine level was found between 0.6-41. When creatinine increase up to around $2.5 \mathrm{mg} / \mathrm{dl}$ may be pre- renal (dehydration or heart failure); creatinine above $5 \mathrm{mg} /$ $\mathrm{dl}$, things are more serious Concentrations of over $10 \mathrm{mg} / \mathrm{dl}$ are seen in acute renal failure, terminal stages of chronic renal failure, rupture of bladder and urethral obstruction. The values obtained from the study showed dogs were having kidney disorders (Kerr 2002). BUN values up to $40 \mathrm{mg} / \mathrm{dl}$ is considered as upper limit and values up to $60 \mathrm{mg} / \mathrm{dl}$ can result from high protein diets. The prognosis of BUN value 200 $\mathrm{mg} / \mathrm{dl}$ is generally poor.Thus, blood urea levels give the best estimation of kidney function, and are diagnostic in about 60-70\% of nephritic cases (Harvey, 2007).Creatinine is eliminated more readily than urea, and therefore an increase in blood creatinine usually is seen later in the course of kidney disease. A concentration of creatinine above $2.0 \mathrm{mg} / 100 \mathrm{ml}$ indicates a reduced Glomerular Filtration Rate ( GFR) (Godkar and Godkar 2005).
Increase in serum amylase is observed with renal diseases, diabetes mellitus, lymphosarcoma, hemangiosarcoma (Strombeck et al., 1981). Increase in serum amylase activity is commonly observed with renal disease in dogs. Ligation of renal vessel results in $60 \%$ increase in serum amylase activity in 48 hours (Hudson \& Strombeck 1978).

Exposure to insecticides and pesticides in sampled cases

Exposure to pesticides and insecticides used in lawn/ garden, and ingestion of flea collar, chemicals used in disinfection, household cleaning might have contributed to establish such conditions. Insecticides, pesticides would affect kidney and liver of dogs. Dogs having chance of getting out and eating garbage and inedible objects like mud organic and chemical fertilizer were also prone to such disorders (Sandhu et al. 2009). Pancreatitis in dogs can happen as a result of accidental contact with the product diazinon. Diazinon is used in several products labeled to kill insects such as cockroaches, ants and fleas. Other symptoms like cell death, interstitial edema and vasculitis are evidence of pancreatitis (Banfield 2010) (fig. 5).
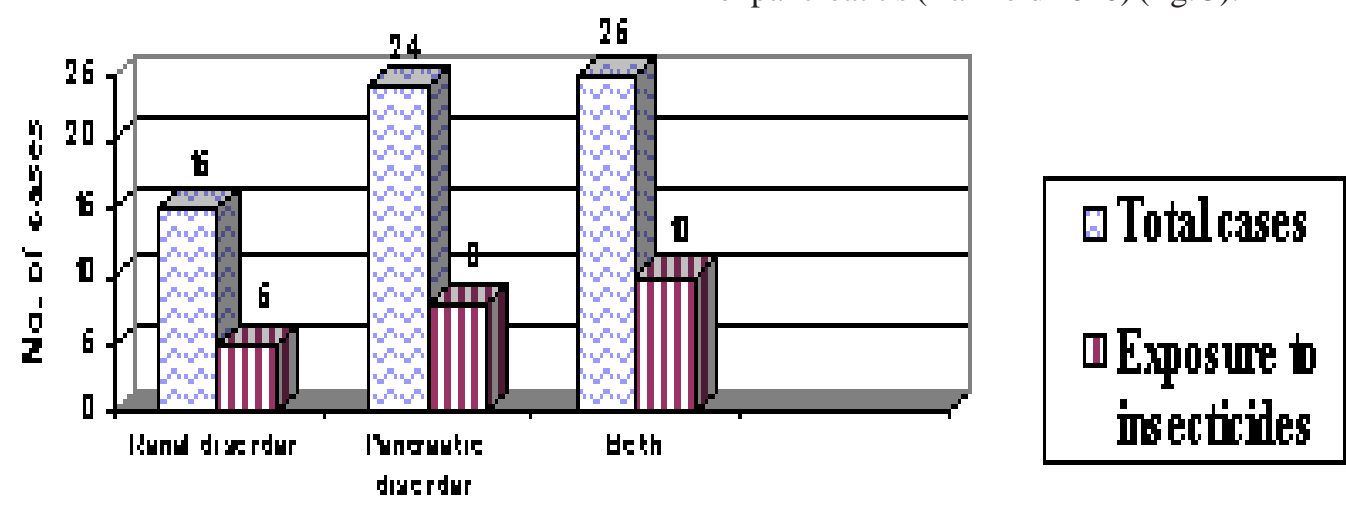

Fig. 5. Exposure to insecticides and pesticides in sampled cases

\section{Presence of Skin Problems along with Renal and Pancreatic disorders}

Out of 62 abnormal ranged samples, 14 were abnormal for renal disorders, out of which 6 were having skin problems. Out of 24 cases for pancreatic disorders, 8 were having skin problems and out of 25 abnormal ranged cases for both disorders, 15 cases were having skin problems which are presented in figure 6.
The frequent use of ivermectin injection might lead to hepatotoxicity and nephrotoxicity (Baidya, 2008). Repeated use of ivermectin had higher incidence for renal disorders. The pancreatic disorders can cause Jaundice in about a third month of patients with chronic pancreatitis (Pandit, 2008). It is usually due to damage to the common bile duct which drains bile from the liver to the duodenum (Ogilvie 2005). 


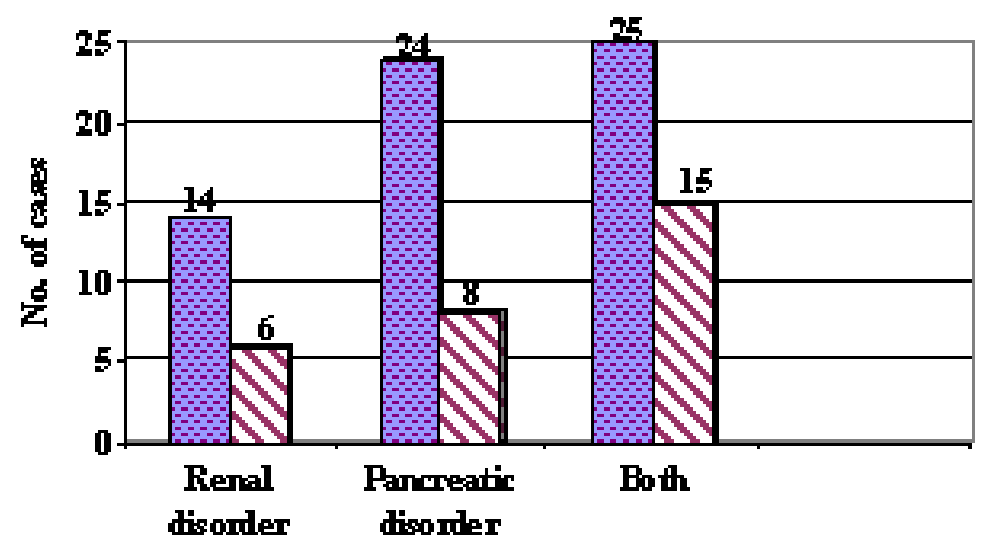

뭉 Tolcases

ธ Skin Problems

Fig. 6 Presence of skin problems along with renal and pancreatic disorders.

\section{Exposure to insecticides and pesticides in sampled cases}

Out of 15 cases of renal disorders, 5 cases had the history of exposure to the insecticides or pesticides used in lawn and had the habit of eating mud. Among
24 cases of pancreatic disorders, 8 cases had history of exposure to insecticides and among 25 cases positive for both disorders, 10 had exposure to insecticides as presented in the Figure 7.

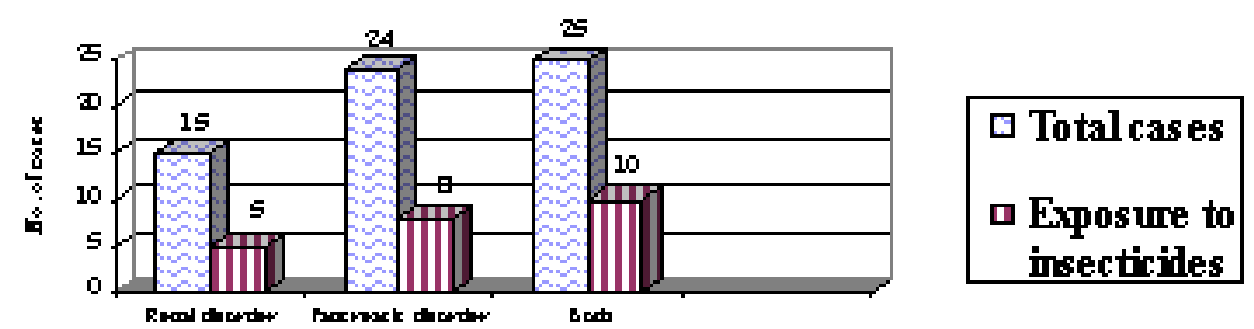

Fig. 7. Exposure to insecticides and pesticides in sampled cases

Exposure to pesticides and insecticides used in lawn/ garden, and ingestion of flea collar, chemicals used in disinfection, household cleaning might have contributed to establish such conditions. Insecticides, pesticides and flea collar would affect kidney and liver of dogs. Dogs having chance of getting out and eating garbage and inedible objects like mud organic and chemical fertilizer were also prone to such disorders (Sandhu et al. 2009). Pancreatitis in dogs can happen as a result of accidental contact with the product diazinon. Diazinon is used in several products labeled to kill insects such as cockroaches, ants and fleas, cell death, Interstitial edema (swelling) and vasculitis (inflammation of blood vessels) are evidence of pancreatitis (Banfield 2010).

\section{References}

Banfield, J. 2010 The Effects of Insecticides on Dogs, (online), Available: www.ehow.com (2 Sept 2010).

Benjamin, M.M. 1985 Outline of veterinary clinical pathology, ${ }^{\text {rd }}$ edition. Kalyani Publishers, New Delhi, Ludhiana, India, pp. 177-178. 
Blood, D.C., Radostitis, M.O., Gay, C.C. \& Hinchcliff, K.W. 2005 A Textbook of diseases of cattle, sheep, pigs, goats and horses, $7^{\text {th }}$ edition. The University printing house, Oxford, pp. 347-485.

Clinical Nutrition Management (CNM). 1998. Geriatric Dogs, Voss Road Animal Hospital, (Online), Available: www.vossroad.com/cnm/html.

Dugdale, D.C. 2010. Pancreatitis Symptoms and Treatment, (Online), Available: www.mosescone.com/body.cfm (20 Jan 2011).

Fogle, B. 2002. Caring for your dog, Dorling Kindersley Limited, London, p. 309.

Godkar, P.B. and Godkar, D.P. 2005. Textbook of Medical Laboratory Technology. $2^{\text {nd }}$ edition, Bhalani Publishing House, India

Harvey, D.G.T. 2005. pp 230 'Biochemical Aspects of Urology’, Journal of Small Animal Practical, 8(6): 327-334.

Hill, R. and Needham, J. 2002 The chemistry of life; eight lectures on history of biochemistry, (Online), Available: www. Sringerlink.com.

Hudson, E.B. and Strombeck, D.R. (1978) 'Effects of functional nephroctomy on disappearance rates of canine serum amylase and lipase', American Journal -1 of Veterinary, (online), Available: www.springerlink.com (10 Dec 2010).
Joshi, D.D., Chhetri, B., Joshi, H. and Sharma, M. 2002 'Dog rabies vaccination and future rabies control plan in 'Kathmandu Valley', National Zoonosis and Food Hygiene Research Centre, Tahachal, Kathmandu, Nepal.

Kerr, M.G. 2002 Veterinary laboratory medicine, $2^{\text {nd }}$ edition. Blackwell Science Vetlab service pp 101.

Kirk, R.W. and Bistner, S.I. 1975 Handbook of Veterinary Pricedures and Emergency Treatment, $2^{\text {nd }}$ edition, W.B Saunders Company Philadelphia/ London/ Toronto.

Medifocus-Guidebook on Chronic Pancreatitis 2011 Chronic Pancreatitis, (online), Available: www.medifocushealth.com/...../chronic-pancreatitis.

Pagana, K.D. 2008 Mosby's manual of Diagnostic and Laboratory Tests, 5th edition, St. Louis, Mosby,Inc, (online), Available: www.webmd.com/digestivedisorders/amylase.

Pancreatitis in Dogs 2011, (Online), Available: www.buzzle.com/article s/pancreatits -In-dogs. html.

Rai, A. 2008 'Study on biochemical evaluation of hepatobiliary and renal disorders in dogs of Kathmandu Valley', B.V.Sc and A.H, Mini-thesis, Purbanchal University, Nepal pp 40.

Sandhu, H.S. and Brar, R.S. 2009 Textbook of veterinary toxicology, 2nd edition. Kalyani Publishers, New Delhi110 002, pp 137 - 195. 